\title{
Kinetics and Mechanism of Oxidation of Pimary Alcohols by Pyridinium Dichromate
}

\author{
HINA HARIT ${ }^{1}$, B. L. HIRAN ${ }^{2}$ and S. N. JOSHI ${ }^{2}$ \\ ${ }^{1}$ Department of Chemistry, S.R.J. Govt. Girls College, Neemuch (M.P.), India \\ ${ }^{2}$ Chemical Kinetics and Polymer Research Laboratory, \\ Department of Chemistry, Mohanlal Sukhadia University, Udaipur (Raj), India \\ hinaharit1@gmail.com
}

Received 21 September 2014 / Accepted 1 October 2014

\begin{abstract}
The kinetics of oxidation of aliphatic alcohols by pyridinium dichromate (PDC) in nonaqueous medium at $303 \mathrm{~K}$ leads to the formation of corresponding aldehydes. In this oxidation reaction $\mathrm{Cr}(\mathrm{VI})$ acts as two electron oxidizing agent. The reaction is first order with respect to each [oxidant], [TsOH] and [Alcohol] The reaction mixture failed to induce the polymerization of added acrylonitrile. The reaction is catalysed by hydrogen ions. The decrease in dielectric constant of the medium increases the rate of the reaction or low dielectric constant of the medium favours the reactivity. The reaction has been conducted at five different temperature and the activation parameters were calculated. The observed experimental data have been rationalized as follows: the intramolecular proton transfer occurs after the prior formation of a dichromate ester in the rate determining step. Negative $\Delta \mathrm{S}^{\#}$ values indicate a structured transition state.
\end{abstract}

Keywords: Kinetics and Mechanism, Oxidation, Pyridinium dichromate, $p$-Toluene sulphonic acid, Dimethyl sulphoxide.

\section{Introduction}

Selective oxidations of alcohols to their corresponding aldehydes and ketones is an important transformation in organic chemistry which has received the most attention over years, especially in the search of versatile and selective reagent for this purpose. Oxidation of alcohols with $\mathrm{Cr}(\mathrm{VI})$ compounds has been extensively investigated. Selective oxidation of organic compounds under non aqueous conditions is an important transformation in synthetic organic chemistry. For this, a number of different $\mathrm{Cr}(\mathrm{VI})$ derivatives have been reported ${ }^{1,2}$. Extensive studies on the mechanism of oxidation of aliphatic alcohols by several oxidants have been reported ${ }^{3}$. The literature on the kinetics of oxidation of aliphatic alcohols with various oxidant shows that the reactivity varies with the type of oxidant. As a part of our investigation on the mechanistic aspects of the $\mathrm{TsOH}$ catalysed $\mathrm{Cr}(\mathrm{VI})$ oxidations, we report the results of the $\mathrm{TsOH}$ catalysed reaction of methanol, ethanol, propan-1-ol and butan-1-ol by PDC in DMSO. In aqueous solutions primary alcohols are usually oxidized to carboxylic acids ${ }^{4}$ while in the absence of water the oxidation will stop at the aldehyde. 


\section{Experimental}

All the chemicals and reagents were of analytical grade. All the solutions used in the study were made by using distilled DMSO. PDC was prepared by reported method ${ }^{5}$ and its purity is checked by an iodometric method. Dimethyl sulphoxide was purified by method given in literature ${ }^{6}$. Due to the non-aqueous nature of the medium, $p$-toluenesulphonic acid (TsOH) was used as a source of hydrogen ions. Due to its nature as a strong acid, TsOH in a polar medium like DMSO is likely to be completely ionised.

\section{Kinetic Measurements}

The reactions were carried out under pseudo first order conditions by keeping an excess of substrate over PDC. The reactions were followed by monitoring the decrease in the concentration of PDC iodometrically for $70 \%$ of the reactions. The rate constants were determined by least square method, from the linear plots of $\log$ [PDC] versus time. Replicate runs showed that the rate constants were reproducible to within $\pm 5 \%$. In correlation analyses, we have used Exner's parameter?

\section{Stoichiometry and product analysis}

The stoichiometry of the reaction was determined by carrying out several sets of experiments with varying amount of [PDC] largely in excess over [alcohol]. The estimation of unreacted PDC showed that three mol of alcohol reacts with 1 mol of PDC.

$$
\begin{aligned}
3 \mathrm{RR}^{\prime} \mathrm{CH}(\mathrm{OH})+\mathrm{PDC} \longrightarrow & \mathrm{P} \longrightarrow \mathrm{RR}^{\prime} \mathrm{C}=\mathrm{O}+2 \mathrm{Cr}(\mathrm{III})+2 \mathrm{H}_{2} \mathrm{O}+2 \mathrm{H}^{+} \\
2 \mathrm{Cr}(\mathrm{VI}) &
\end{aligned}
$$

The product analysis was carried out under kinetic conditions. In a typical experiment, Butan-1-ol $(0.05 \mathrm{~mol})$ and PDC $(0.005 \mathrm{~mol})$ were made up to $50 \mathrm{~cm}^{3}$ in DMSO and kept $20 \mathrm{~h}$ to ensure completion of the reaction, was then treated with excess $\left(200 \mathrm{~cm}^{3}\right)$ of 2, 4-DNP in $2 \mathrm{M} \mathrm{HCl}$ and was kept overnight in a refrigerator. The precipitated 2,4 dinitrophenyl hydrazones was filtered off, dried, weighed and recrystallized from ethanol and melting point was then determined. The DNP was found identical (m.pt. and mixed m.pt.) with the DNP of butaraldehyde.

\section{Results and Discussion}

The kinetics of oxidation of aliphatic alcohols by PDC was investigated at several initial concentrations of the reactants. The reaction proceeds smoothly at $303 \mathrm{~K}$ in non aqueous DMSO medium and the observed results are discussed below.

\section{Test for free radicals}

The oxidation of alcohols by PDC, in an atmosphere of nitrogen, failed to induce polymerization of acrylonitrile. In blank experiments, with the substrate absent, no noticeable consumption of PDC was observed. The addition of acrylonitrile had no effect on the rate of oxidation.

\section{Effect of oxidant concentration}

At constant [substrate] and [TsOH], the increase in [PDC] did not affect the rate of reaction. The first order plots of log [PDC] vs. time were linear. The pseudo first order rate constants computed from the plots remained unaffected by the change in [PDC], establishing the first order dependence of the rate on pyridinium dichromate in all cases. 


\section{Effect of substrate concentration}

At constant [PDC] and [TsOH], the increase in [substrate] enhances the reaction rate. The plot of $\log \mathrm{k}_{\mathrm{obs}}$ versus $\log$ [substrate] for different initial concentration of substrate is linear with unit slope indicating the first order dependence on substrate (Table 1). The order of the reaction with respect to the substrate i.e., methanol, ethanol, propan-1-ol and butan-1-ol is $1.04,1.14,0.97$ and 1.11 respectively. A plot of $\mathrm{k}_{\mathrm{obs}} v \mathrm{v}$. [Alcohol] is shown in Figure 1. A plot of $\mathrm{k}_{\mathrm{obs}}{ }^{-1}$ versus [alcohol] ${ }^{-1}$ show negligible intercept on the rate axis, indicating the Michaelis-Menten independence on the concentration of the substrate (Figure 2).

Table 1. Variation of rate with substrate concentration

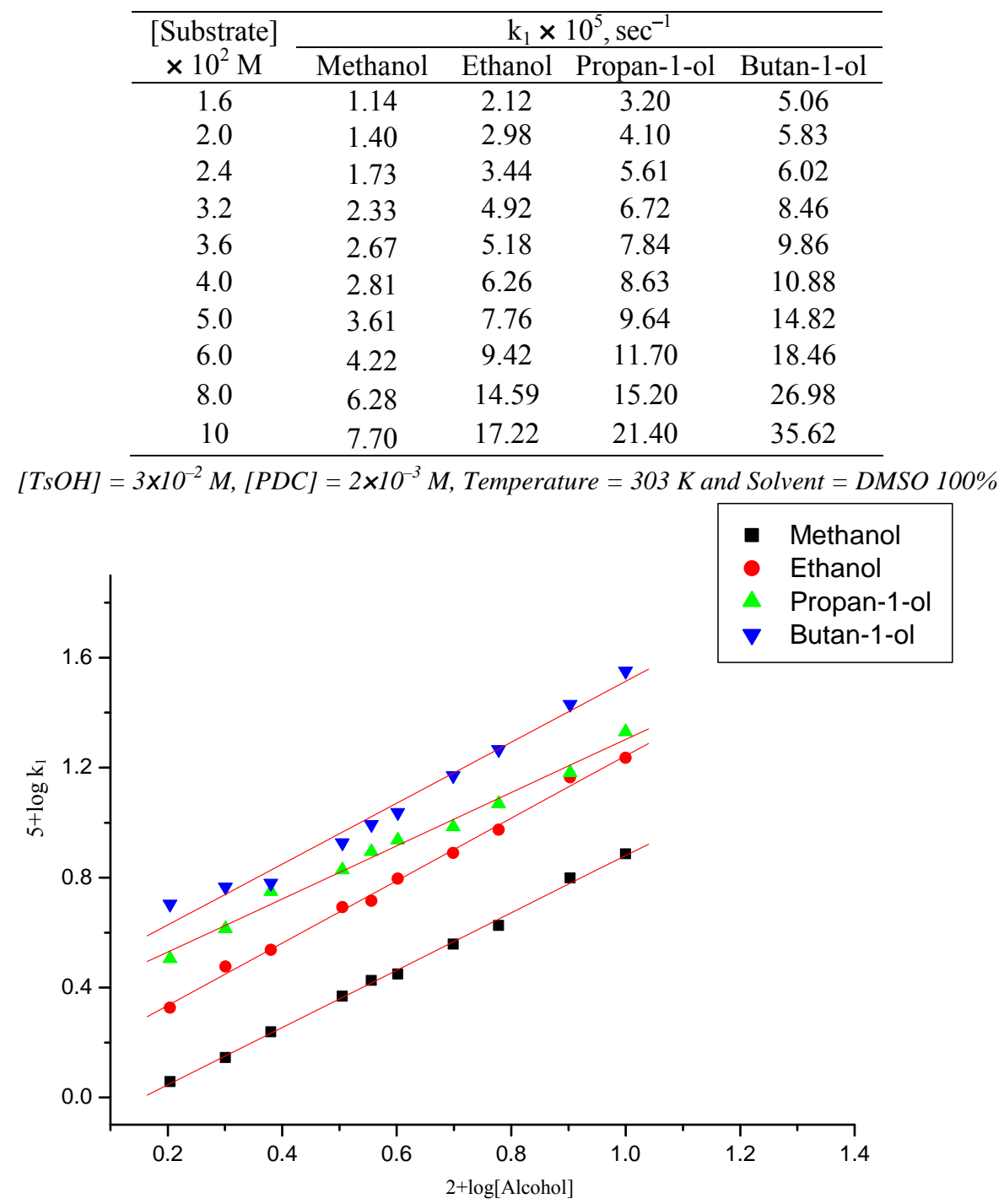

Figure 1. Variation of rate with substrate concentration 


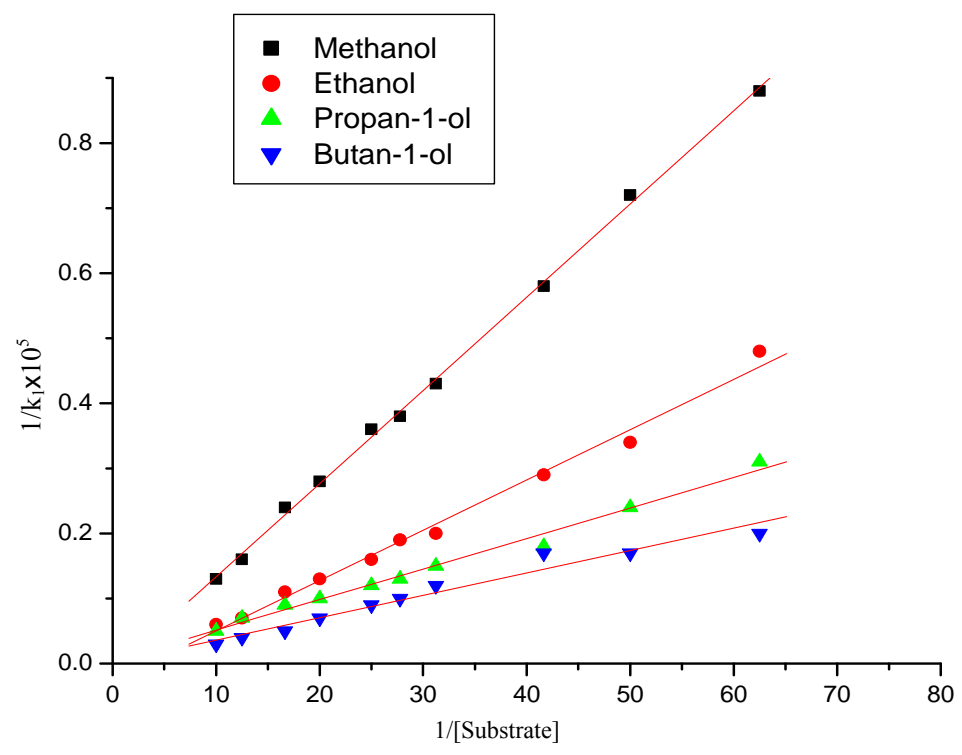

Figure 2. Variation of rate with substrate

\section{Effect of TsOH concentration}

The reaction is catalyzed by hydrogen ion; the acid catalysis may well be attributed to the protonated ion of PDC to give a stronger oxidant and electrophile. The rate of reaction increases with increase in TsOH concentration. The plot of $\log \mathrm{k}_{\mathrm{obs}}$ versus $\log \left[\mathrm{H}^{+}\right]$are also straight line with unit slope, indicating a first order dependence on $\left[\mathrm{H}^{+}\right]$is shown in Table 2. $\mathrm{TsOH}$ enhances the conversion of aliphatic alcohols. The rate of oxidation increases with an increase in acidity and the dependence is of the form - Rate $=\mathrm{k}^{\prime}\left[\mathrm{H}^{+}\right]$. The order with respect to hydrogen ion in methanol, ethanol, propan-1-ol and butan-1-ol is $0.93,0.97,1.11$ and 0.91 respectively. The log-log plot of $\mathrm{k}_{\mathrm{obs}} v \mathrm{vs} .\left[\mathrm{H}^{+}\right]$, for aliphatic alcohols is shown in Figure 3.

Table 2. Variation of rate with $\mathrm{TsOH}$ concentration

\begin{tabular}{ccccc}
\hline$[\mathrm{TsOH}]$ & \multicolumn{4}{c}{$\mathrm{k}_{1} \times 10^{5}, \mathrm{sec}^{-1}$} \\
\cline { 2 - 5 }$\times 10^{2} \mathrm{M}$ & Methanol & Ethanol & Propan-1-ol & Butan-1-ol \\
\hline 1.5 & - & 1.51 & 2.28 & 3.06 \\
2.0 & 1.07 & 2.04 & 2.67 & 4.15 \\
2.5 & 1.23 & 2.43 & 3.28 & 5.30 \\
3.0 & 1.42 & 2.86 & 4.21 & 5.91 \\
3.5 & 1.71 & 3.48 & 5.63 & 7.21 \\
4.0 & 1.93 & 4.07 & 6.18 & 8.43 \\
4.5 & 2.19 & 4.38 & 7.04 & 8.71 \\
5.0 & 2.44 & 5.12 & 8.17 & 11.09 \\
\hline
\end{tabular}

[Alcohol] $=2 \times 10^{-2} \mathrm{M},[\mathrm{PDC}]=2 \times 10^{-3} \mathrm{M}$, Temperature $=303 \mathrm{~K}$ and Solvent $=\mathrm{DMSO} 100 \%$

\section{Effect of solvent composition}

At fixed ionic strength and $\left[\mathrm{H}^{+}\right]$of $\mathrm{TsOH}$, the rate of oxidation of alcohols with PDC increases with decrease in polarity of solvent. The oxidation was studied in solutions containing varying proportions of DMSO and Acetone (Table 3). Permittivity (D) values for 
DMSO : Acetone were estimated from the dielectric constants of the pure solvents ${ }^{8}$ and are recorded. Low values of relative permittivity (dielectric constant), $\varepsilon_{\mathrm{r}}$ of the medium favours the reactivity. An increase in rate with decrease in dielectric constant of solvent is observed. According to Scatchard ${ }^{9}$ if reaction involves ion-dipole type of interaction than the $\log \mathrm{k}_{1}$ of a reaction between ions should vary linearly with $1 / \mathrm{D}$ (Table 3 ). A plot of $\log \mathrm{k}_{1}$ against the inverse of permittivity (1/D) is linear with a positive slope (Figure 4$)$. This suggests an iondipole interaction in agreement ${ }^{10}$ with the observation that in the presence of an acid, the rate-determining step involves a protonated $\mathrm{Cr}$ (VI) species. The increase in rate caused by the decrease in solvent polarity was attributed to an equilibrium shift favouring the formation of dichromate ester ${ }^{11}$.

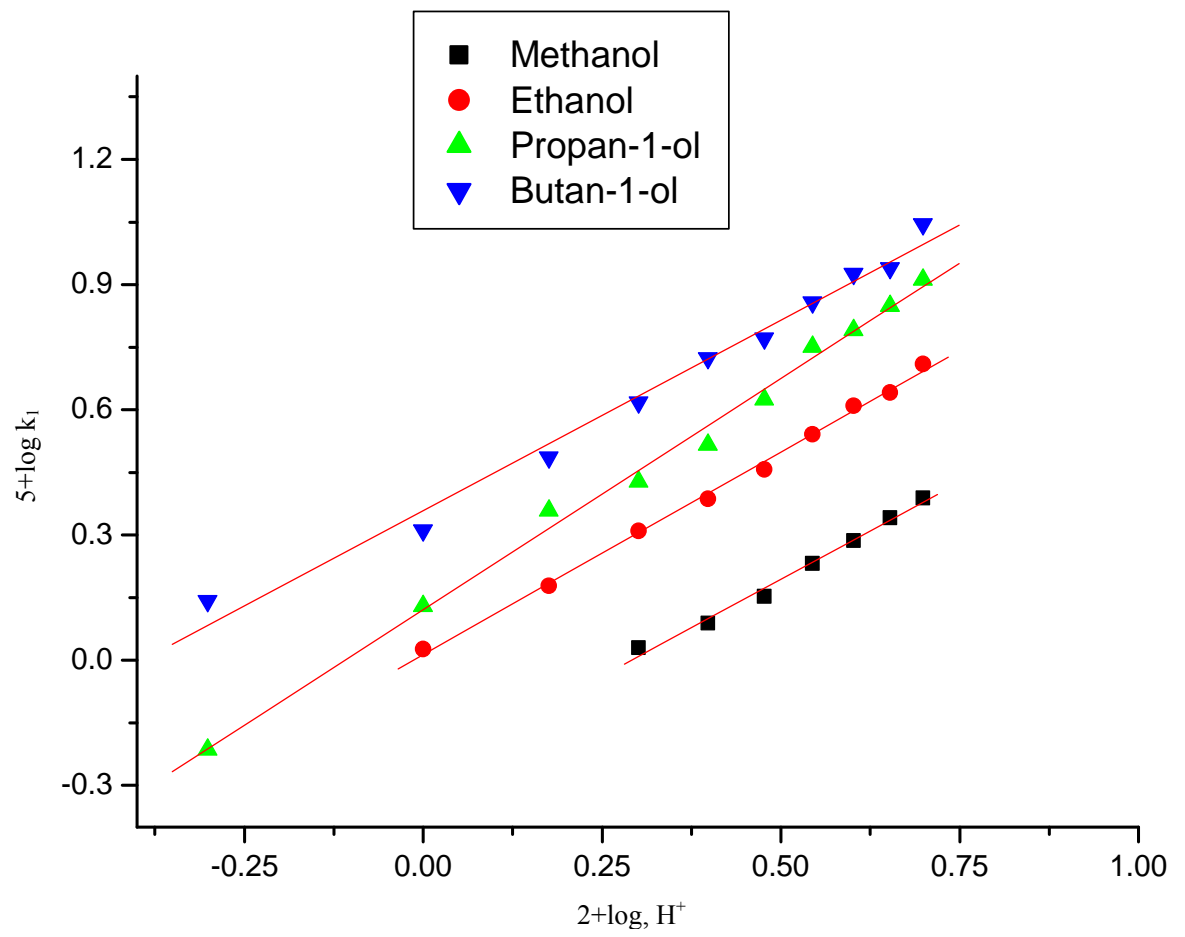

Figure 3. Variation of Rate with TsOH Concentration

Table 3. Dependence of the reaction rate on solvent composition

\begin{tabular}{cccccccc}
\hline & \multicolumn{6}{c}{$\mathrm{k}_{1} \times 10^{5}, \mathrm{sec}^{-1}$} \\
\cline { 2 - 7 } $\begin{array}{c}\text { Acetone } \\
\% \mathrm{v} / \mathrm{v}\end{array}$ & $\begin{array}{c}\mathrm{D}-1 \\
/ 2 \mathrm{D}+1\end{array}$ & $\begin{array}{c}\text { Mole } \\
\text { Fraction } \\
\text { of DMSO }\end{array}$ & $\begin{array}{c}(1 / \mathrm{D}) \times \\
10^{3}\end{array}$ & Methanol & Ethanol & Propan-1-ol & Butan-1-ol \\
\hline 00 & 24.60 & 1 & 21.2 & 1.41 & 2.99 & 4.15 & 5.98 \\
10 & 23.31 & 0.903 & 22.4 & 1.49 & 3.22 & 4.75 & 6.74 \\
20 & 22.03 & 0.806 & 23.8 & 1.57 & 3.55 & 5.18 & 7.85 \\
30 & 20.72 & 0.707 & 25.4 & 1.78 & 3.96 & 5.83 & 8.44 \\
40 & 19.41 & 0.608 & 27.2 & 1.97 & 4.57 & 6.38 & 9.26 \\
50 & 18.08 & 0.508 & 29.3 & 2.28 & 5.41 & 7.83 & 12.28 \\
\hline
\end{tabular}

$[\mathrm{PDC}]=0.002 \mathrm{M},[$ Alcohol $]=0.02 \mathrm{M},[\mathrm{TsOH}]=0.03 \mathrm{M}$ and $\mathrm{T}=303 \mathrm{~K}$ 


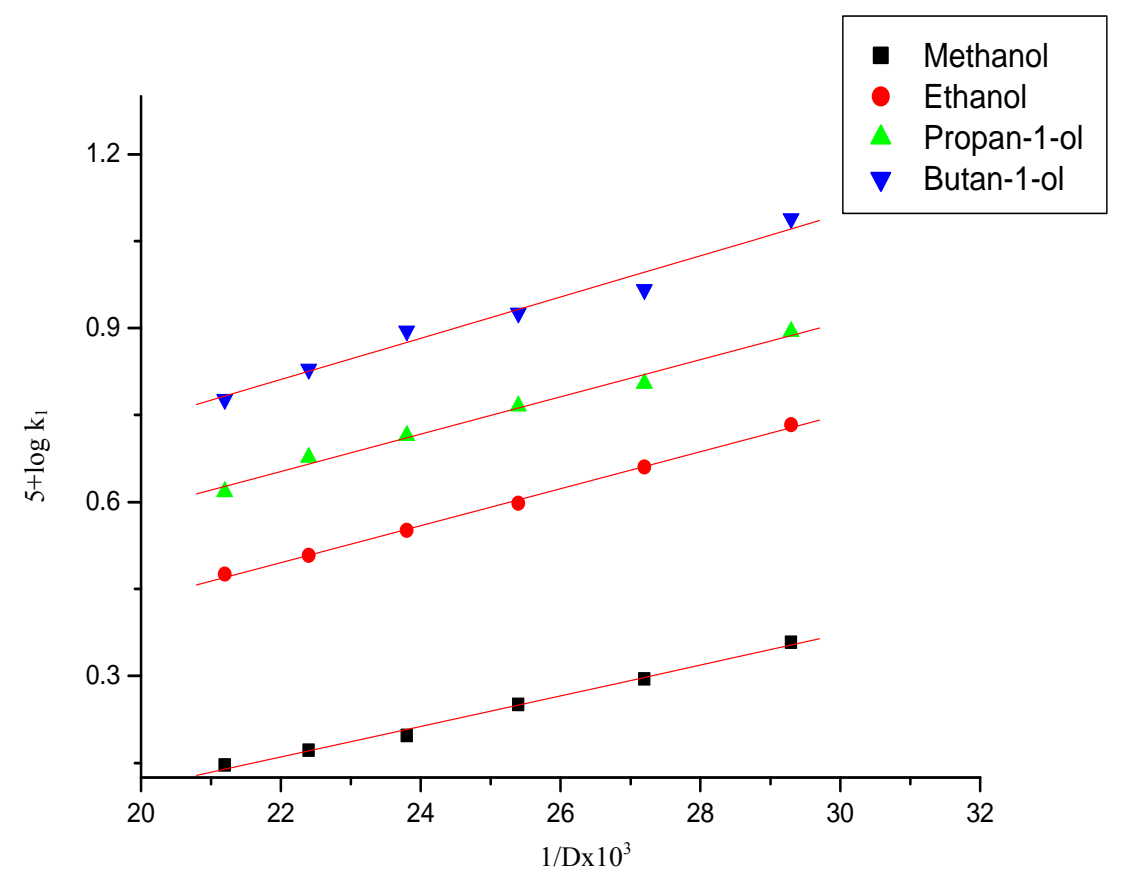

Figure 4. Variation of rate with solvent composition

\section{Effect of temperature}

The study of oxidation of different alcohols has been subjected to different temperature range $303 \mathrm{~K}$ to $323 \mathrm{~K}$ by keeping the concentration of substrate and reagent constant. The rate constants are given in Table 4 . The plots of $\log \mathrm{k}_{\mathrm{obs}}$ versus $1 / \mathrm{T}$ are linear (Figure 5).

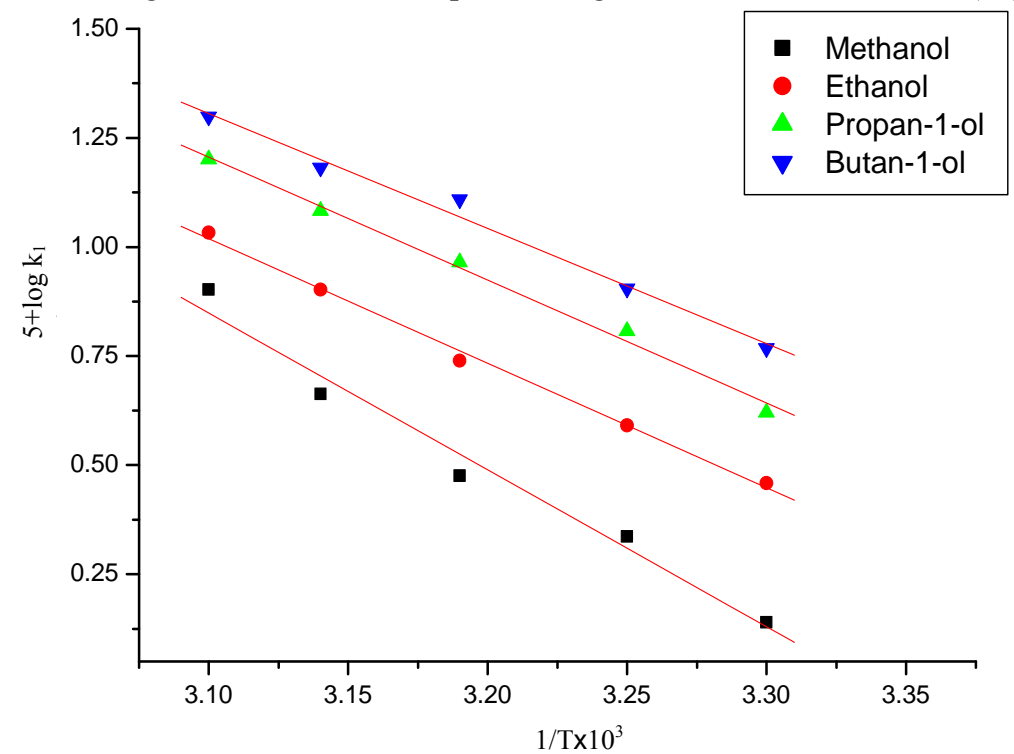

Figure 5. Variation of rate with temperature 
The activation parameters have been calculated using the Eyring's plot $^{12}$ and the activation parameters were obtained from the slope and intercept of the Eyring's plot (Table 5). The negative values of entropy of activation reflect that suggests that the solvent molecules are strongly oriented around the ions, which results in the loss of entropy ${ }^{13}$, the effect being larger in non-polar solvents. This confirms that, the decrease of polarity of medium results in increase of the entropy values and the number of unbound molecules in the solution increases ${ }^{14}$. The nearly constant $\Delta \mathrm{G}$ value indicates that similar mechanism is operative for the oxidation of alcohols (Table 5).

Table 4. Temperature dependence of the oxidation of aliphatic alcohols by PDC

\begin{tabular}{ccccc}
\hline \multirow{2}{*}{ Temp. K } & \multicolumn{4}{c}{$\mathrm{k}_{1} \times 10^{5}, \mathrm{sec}^{-1}$} \\
\cline { 2 - 5 } & Methanol & Ethanol & Propan-1-ol & Butan-1-ol \\
\hline 303 & 1.38 & 2.88 & 4.18 & 5.86 \\
308 & 2.17 & 3.90 & 6.41 & 8.04 \\
313 & 2.99 & 5.49 & 9.23 & 12.84 \\
318 & 4.60 & 7.98 & 12.10 & 15.20 \\
323 & 7.98 & 10.78 & 15.90 & 19.92 \\
\hline
\end{tabular}

$[\mathrm{PDC}]=0.002 \mathrm{M},[$ Alcohol $]=0.02 \mathrm{M},[\mathrm{TsOH}]=0.03 \mathrm{M}$ Solvent $=\mathrm{DMSO} 100 \%$

Table 5. Thermodynamic parameters of aliphatic alcohols

\begin{tabular}{ccccc}
\hline Alcohols & $\begin{array}{c}\Delta \mathrm{E}^{\#} \\
\mathrm{~kJ} \mathrm{~mol}^{-1}\end{array}$ & $\begin{array}{c}\Delta \mathrm{H}^{\#} \\
\mathrm{~kJ} \mathrm{~mol}^{-1}\end{array}$ & $\begin{array}{c}\Delta \mathrm{S}^{\#} \\
\mathrm{~J} \mathrm{~mol}^{-1} \mathrm{~K}^{-1}\end{array}$ & $\begin{array}{c}\Delta \mathrm{G}^{\#} \\
\mathrm{~kJ} \mathrm{~mol}^{-1}\end{array}$ \\
\hline Methanol & 60.57 & 58.05 & -79.89 & 84.78 \\
Ethanol & 54.57 & 52.05 & -93.58 & 82.93 \\
Propan-1-ol & 53.83 & 51.31 & -92.96 & 81.99 \\
Butan-1-ol & 50.19 & 47.67 & -102.14 & 81.14 \\
\hline
\end{tabular}

Energy-entropy relationship

The entropy of activation and heat of reaction are correlated by the equation (a).

$$
\Delta \mathrm{H}^{\#}=\Delta \mathrm{H}^{0}+\beta \Delta \mathrm{S}^{\#}
$$

Where $\beta$ is the isokinetic temperature, the isokinetics temperature for the reactions between alcohols and PDC in non aqueous DMSO, which is greater than experimental temperature. The values of free energies of activation of reaction were found to be more or less similar. These trends also support the identical reaction mechanism being followed in these reactions ${ }^{15}$. The linear relationship in Exner is observed. The Exner plot for aliphatic alcohols and cyclic alcohols between $\log \mathrm{k}_{1}(303 \mathrm{~K})$ versus $\log \mathrm{k}_{1}(313 \mathrm{~K})$ is linear $(\mathrm{r}=0.99)$ and the isokinetic temperature $\beta$ obtained from the slope is $466.40 \mathrm{~K}(\mathrm{r}=$ 0.99) (Figure 6).

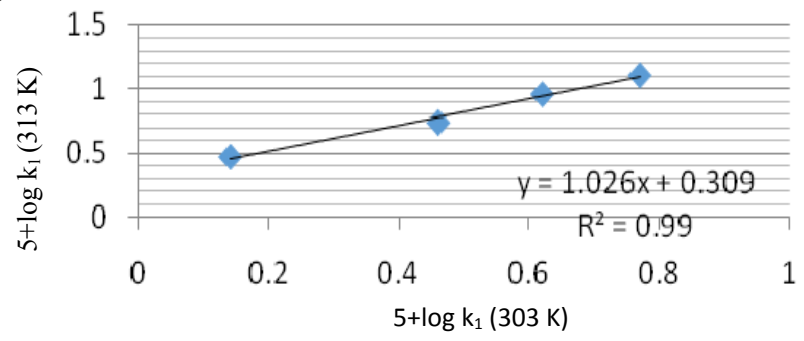

Figure 6. Exner Plot for aliphatic alcohols 
The plot of log absorbance against time is found to be linear, showing first order dependence in PDC. A plot of $\log \mathrm{k}_{1}$ vs. $\log$ [Alcohol] gave a straight-line with slope $\approx 1$ showed first order dependence over substrate. A study increase in the oxidation rate with an increase in the acidity of the medium suggests the formation of protonated PDC. The plot of $\log \mathrm{k}_{1}$ against $\log \left[\mathrm{H}^{+}\right]$is linear with a slope of nearly one.

Since the protonation of alcohol is less probable it is more likely that the proton is used by the oxidant, PDC. TsOH acts as a proton donating agent. Solvent dimethyl sulphoxide acts as a weak nucleophile it helps in the dissociation of $\mathrm{H}^{+}$ion from TsOH because DMSO is a powerful hydrogen bond acceptor, earlier shown by Kingsbury ${ }^{16}$. The formation of chromate ester as an intermediate in a pre-equilibrium step has been reported earlier in chromic acid oxidation ${ }^{17}$, PDC, QDC etc. ${ }^{18}$ in nitrobenzene-dichloromethane mixtures ${ }^{19}$. The protonated PDC and alcohol combine to give intermediate, which was also indicated by increase in rate with decrease in dielectric constant of reaction medium. The rate determining step is the decomposition of the chromate ester via cyclic transition state and it involves the ruptures of $\alpha \mathrm{C}-\mathrm{H}$ bond and forming the product ${ }^{20,21}$. It has been reported that the chromate ester has greater stability in organic solvents than in water ${ }^{22-23}$. The large negative $\Delta S^{\#}$ values implies the formation of a chromate ester with a high degree of orderedness supporting cyclic intermediate formation.

Thus a planar, cyclic and symmetrical transition state can be envisaged for the decomposition of the ester intermediate. The overall mechanism proposed is involving the formation of a chromate ester in a fast pre-equilibrium step and then decomposition of the ester intermediate in a subsequent slow step via a cyclic concerted symmetrical transition state giving the product. The mechanism proposed is presented as:

\section{Mechanism}<smiles>O=S(=O)(O)c1ccccc1</smiles><smiles>O=S(=O)([O-])c1ccccc1</smiles>

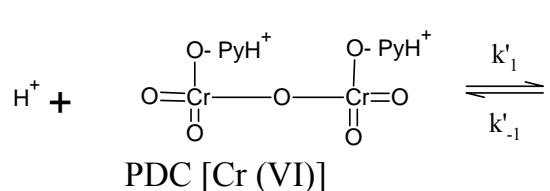

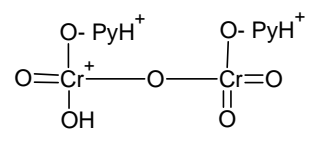

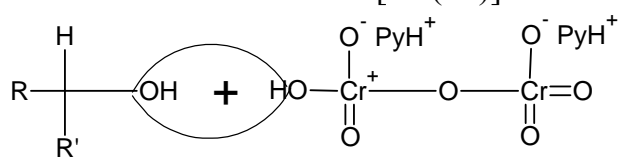

[Alcohol]

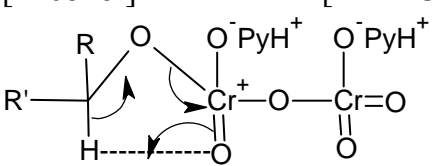

[C]

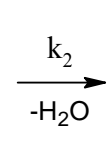

Protonated PDC [Cr(V)-O-Cr(VI)]

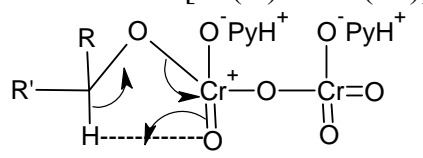

[C] $\underset{\text { Slow } \mathrm{k}_{3}}{\stackrel{\mathrm{RDS}}{\longrightarrow}}$

$$
\mathrm{Cr}(\mathrm{IV})-\mathrm{O}-\mathrm{Cr}(\mathrm{VI}) \quad \stackrel{\text { Fast }}{\longrightarrow}
$$<smiles>[R]C([R])=O</smiles>

[Aldehyde]

$2 \mathrm{Cr}(\mathrm{V})-\mathrm{O}-\mathrm{Cr}(\mathrm{V})$ 


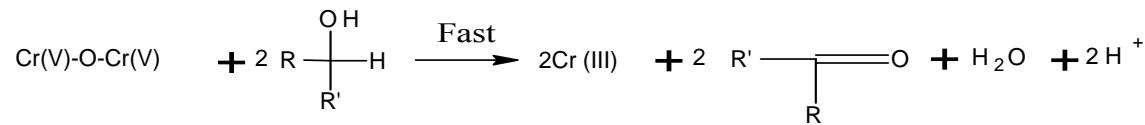

Where $\mathrm{R}^{\prime}$ is alkyl group and $\mathrm{R}$ is $\mathrm{H}$.

Overall reaction

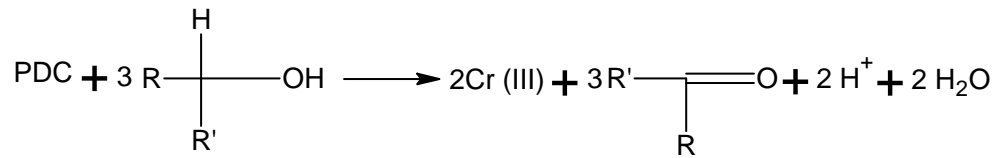

Rate Law

Rate $=\mathrm{k}^{\prime}$ [Oxidant] [Substrate $\left[\mathrm{H}^{+}\right]$

Rate $=\mathrm{k}_{\text {obs }}[$ Oxidant]

$\mathrm{k}_{\text {obs }} \quad=\mathrm{k}^{\prime} /[$ Substrate $]\left[\mathrm{H}^{+}\right]$

The proposed mechanism and the derived rate law fit well to the experimental observations.

\section{Conclusion}

The oxidation of primary aliphatic alcohols involves the formation of dichromate ester which on decomposition giving the product. The reaction was first order with respect to substrate and $\mathrm{TsOH}$ concentration. No change in the rate of reaction on polymerization in the presence of acrylonitrile confirms a two-electron transfer reaction. Both deprotonated and protonated forms of PDC are the reactive oxidising species. A $\alpha \mathrm{C}-\mathrm{H}$ bond is cleaved in rate-determining step.

\section{References}

1. (a) $\mathrm{Li} \mathrm{M}$ and Johnson $\mathrm{M}$ E, Synth Commun., 1995, 25(4), 533-537; DOI:10.1080/00397919508011387 (b) Firouzabadi H and Sharifi A, Synthesis, 1992, 999-1002; (c) Baltroke I M, Sadeghi M M, Mahmoodi N and Kharmesh B, Indian J Chem., 1997, 36B, 438.

2. (a) Corey E J and Suggs W J, Tetrahedron Lett., 1997, 16(31), 2647-2650; DOI:10.1016/S0040-4039(00)75204-X (b) Bhattacharjee M N, Chaudhuri M K, Dasgupta H S, Roy N and Kathing D T, Synthesis, 1982, 588-590.

3. (a) Sharma P K and Baghmar M, Proc Indian Acad Sci (Chem Sci)., 2001, 113(2), 139-146; (b) Jameel A A, J Indian Chem Soc., 1999, 76, 263-265; (c) Banerji K K, Choudhary K and Sharma P K, Int J Chem Kinet., 1999, 31(7), 469-475; DOI:10.1002/(SICI)1097-4601(1999)31:7<469::AID-KIN1>3.0.CO;2-2 (d) Banerji K K, Kothari A and Kothari S, Indian J Chem., 2005, 44A, 2039-2043; (e) Banerji K K, Banerji J and Sharma P K, Indian J Chem., 2008, 47A, 1213-1217; (f) Meenakshisundaram S and Sockalingam R, Collect Czech Chem Commun., 2001, 66(6), 877-896; (g) Mansoor S S and Shafi S S, Arabian J Chem., 2014, 7(3), 312-318; DOI:10.1016/j.arabjc.2010.11.004 (h) Saraswat S, Vinita Sharma and Banerji K K, Proc Indian Acad Sci (Chem Sci.), 2003, 115(1), 75-82; (i) Patwari S B, Khansole S V and Vibhute Y B, Bull Catal Soc India, 2009, 8, 114-120; (j) Palaniappan A N, Vaideki S, Srinivasan S and Raju C, Der Chemica Sinica, 2012, 3(1), 192-197; (k) Shamell A and Gharib F, J Phys Theoretical Chem., 2009, 5(4), 209-214; (1) Sapna Jain, Hiran B L and Bhatt C V, E-J Chem., 2009, 6(1), 237-246; DOI:10.1155/2009/907071 
4. (a) Lee D G and Spitzer U A, J Org Chem., 1970, 35(10), 3589-3590; DOI:10.1021/jo00835a101 (b) Robertson G R, Org Synth Coll., 1941, 1, 138.

5. Corey E J and Schmidt G, Tetrahedron Lett., 1979, 20(5), 399-402;

DOI:10.1016/S0040-4039(01)93515-4

6. Perrin D D, Armarego W L and Perrin D R, Purification Organic compounds, Pergamon Press, Oxford, 1966.

7. $\quad$ Exner O, Collect Czech Chem Commun., 1966, 31(8), 3222-3251; DOI: $10.1135 /$ cccc19663222

8. Furniss B S, Hannaford A J, Smith P W G and Tatchell A R, Vogel's Textbook of Practical Organic Chemistry, John Wiley \& Sons, New York, 1989, 1442.

9. (a) Scatchard G, J Chem Phys., 1939, 7(8), 657; DOI:10.1063/1.1750510 (b) Scatchard G, Chem Rev., 1932, 10, 229.

10. Amis E S, Solvent effects on reaction rates and mechanisms, Academic Press, New York, 1967, 42.

11. Westheimer F H, Chem Rev., 1949, 45(3), 419-451; DOI:10.1021/cr60142a002

12. Eyring H, J Chem Phy., 1935, 33, 107- 114.

13. Basolo F and Pearson R G, Mechanism of Inorganic Reaction: A study of metal complexes in solution, 1973, II, 129.

14. Cotton F A and Wilkinson G, Adv Inorg Chem., 1976, III, 169.

15. Gowda T and Mary M C, Indian J Chem., 2001, 40(A), 1196.

16. (a) Chapman O L and King R W, J Am Chem Soc., 1964, 86(6), 1256-1258; DOI:10.1021/ja01060a068 (b) Barnard D, Fabian J M and Koch H P, J Chem Soc., 1949, 2442-2454; DOI:10.1039/JR9490002442 (c) Allerhand A and Schleyer P V R, J Am Chem Soc., 1963, 85(12), 1715-1723; DOI:10.1021/ja00895a002 (d) Kingsbury C A, J Org Chem., 1964, 29(11), 3262-3270; DOI:10.1021/jo01034a032

17. Wiberg K B, Oxidation in Organic Chemistry, Part A; Academic Press New York, $1965,69$.

18. (a) Dey D and Mahanti M K, J Org Chem., 1990, 55(23), 5848-5850; DOI:10.1021/jo00310a015 (b) Dangarh B K, Hiran B L and Joshi S N, Oxid Commun., 2012, 35(2), 352-361; (c) Choudhary J, Inter J Chem Appl., 2013, 5(1), 45-53; (d) Kabilan S, Girija R, Reis J C R, Segurado M A P and de Oliveria J D G, J Chem Soc Perkin Trans., 2002, 2, 1151-1157; DOI:10.1039/B200742H

19. (a) Banerji K K, J Chem Res., Miniprint., 1978, 2561; (b) Banerji K K, Ind J Chem., 1979, 17A, 300.

20. Banerji K K, J Org Chem., 1988, 53(10), 2154-2159; DOI:10.1021/jo00245a004

21. Banerji K K, Eur Chem Bull., 2013, 2(10), 816-824.

22. Beattie J K and Haight G P, Progr Inorg Chem Inorganic Reaction Mechanism, 1972, (II)17, 93-145.

23. Wiberg K B and Schafer H, J Am Chem Soc., 1969, 91, 927-932;

DOI:10.1021/ja01032a023 